\title{
NSU-LSMSA Makers Club: STEM Educational Modules and Quality Assur- ance Education
}

\section{Dr. Jafar F. Al-Sharab, Northwestern State University}

Dr. Jafar Farhan Al-Sharab has recently joint the faculty in the Engineering Technology Department at Northwestern State University as an assistant professor. Jafar F. Al-Sharab received BS In Industrial Engineering from the University of Jordan, MS in Metallurgical Engineering from the Science University of Malaysia, and PhD in Materials Science and Engineering from Vanderbilt University/Nashville, TN. Prior joining NSU, Professor Al-Sharab was and Instructional and Research Faculty at Rutgers University. At Rutgers, he was heavily involved in research and teaching at both graduate and undergraduate levels. In the period of 2011-2014, Dr. Al-Sharab was a visiting professor in the Department of Mechanical and Aerospace Engineering at New York University Polytechnic School of Engineering. In addition to his work with academic institutions, Dr. Al-Sharab was a consultant of various technological companies especially in the areas of structure-property-correlations and advanced characterizations. Dr. Al-Sharab's research interests are in the areas of Nanotechnology, Electron Microscopy, Structure-property correlations, synthesis and characterization of energy related materials (harvesting and storage), flame retardant polymers, nanocompsite materials, and advanced materials characterization. He is an active member of professional organizations related to his research interests. He has authored more than 40 technical papers.

Dr. Adeal Sobhe Matuk, Rutgers University, Department of Materials Science and Engineering, and Anbar University, Department of Physics

Adeal Sobhe Matuk is a Ph.D. Candidate in Materials Science \& Engineering at Rutgers University, New Brunswick, NJ Adeal S. Matuk received BS of Science in Physics Anbar University, College of Science, Iraq, MSc of Science in Physics Bagdad University, College of Science, Iraq. Adeal research interests are in the areas of Nanotechnology which includes synthesis Techniques: Melt-quenching for glasses, Solid-state reaction and Sol-gel for ceramics, Solution casting for polymers and polymers-ionic liquid complexes. Experimental Techniques: dip and spin Coating Deposition, Thermal Evaporation, Electron-beam Sputter Deposition, Thin film Device Fabrication, Dark-Field Microscopy, Photoluminescence Spectroscopy, X-ray diffraction, Scanning electron microscopy (SEM), Optical microscopy, UV-Vis. He is an active member of professional organizations related to his research interests. He has authored some technical papers.

\section{Mr. Curtis Paul Desselles Jr.,}

I am the Engineering Laboratory Coordinator at Northwestern State University of Louisiana (NSULA). My specialty is robotics and building and designing scientific devices. My experience is as follows: Retired U.S. Navy Medical Laboratory Technologist and Physician's Assistant (P.A.). I worked as a Research Fellow at National Center for Preservation Technology and Training (NCPTT) following my career in the Navy. I also work as a robotics instructor at the Louisiana School for Math Sciences and the Arts (LSMSA). My education is as follows: B.S. Physics from University of Maryland. B.A., M.A. Anthropology from NSULA. I teach four robot camps every summer and hold various science seminars throughout the year at the local library.

\section{Dr. Robert Dalling}

Dr. Robert Dalling has been teaching at LSMSA since 2006. He finds it a privilege to teach LSMSA's students who are all intellectuals and wonderful people. In 1992 he received his Ph.D. in physics, with an engineering minor involving fluid mechanics and nuclear engineering, from New Mexico State University

\section{Dr. Mauricio J Escobar Medina Medina}

Dr. Mauricio Escobar was born in Barranquilla, Colombia. He earned his Bachelor's degree in Mathematics and Physics in 2002. During this time, he taught in small institutes and as a private tutor, and worked in several local high schools and colleges. In 2006, Dr. Escobar left his country of origin to 
pursue his Master's degree in Physics at the University of Puerto Rico at Mayaguez, Puerto Rico, which he earned in 2009. Soon after, Dr. Escobar was admitted in the Physics doctoral program at the University of Rhode Island, in Kingston, Rhode Island. In 2015, Dr. Escobar completed his doctoral thesis dissertation on Quantum Diffusion of Ultra-Cold Neutrons in Rough Waveguides. Shortly after, Dr. Escobar worked as visiting Assistant Professor at the University of Nebraska at Kearney and he joined the faculty at Louisiana School for Math, Science \& the Arts in Fall 2016, as Physics Instructor.

\section{William Spencer Heitman}

William Heitman is a high school student at the Louisiana School for Math, Science, and the Arts. He is currently conducting robotics research sponsored by the Louisiana School and Northwestern State University.

\section{Miss Ariell Nashalette Shield}

Ariell Shield is a student at Northwestern State University in Natchitoches, Louisiana. Her interests are in Electronics Engineering Technology. In summer 2016 she was an intern at University of at Texas at Dallas she conducted a research related to Titanium Dioxide (TiO2) -ethylenedioxythiophene nanocomposites 


\title{
NSU- LSMSA Makers Club: STEM Educational Modules and Quality Assurance Education
}

\begin{abstract}
:
Makers Clubs are a national movement which gets students exited about STEM and helps to increase the number of students interested in STEM related careers. This paper describes a STEM makers club, which combines Northwestern State University (NSU) and The Louisiana School for Math, Science, and the Arts (LSMSA). The newly founded club (NSULSMSA Makers Club), emphasizes innovation and hands-on experience for all participants. In addition, the club promotes building a spirit of teamwork and sharping problem-solving skills. Participants have access to the scientific facilities and a venue that allows them to develop and enhance their scientific thinking as well their scientific knowledge under proper mentorship. Different teaching modules, including engineering graphics, soldering techniques, digital electronics, energy harvesting, energy storage, and electromagnetism have been developed and applied. Additionally, quality assurance was also introduced for the first time as a STEM module. The NSU-LSMSA makers club represents a successful and a true manifestation of STEM education at high school including collaboration with higher educational institution.
\end{abstract}

\section{Introduction:}

Efforts to improve science, technology, engineering, and mathematics (STEM) education in grades K-12 are not new. Since the 1960s there have been lots of efforts to develop curriculum projects for science and mathematics. As a matter of fact we currently even have national standards documents to implement such STEM education. Yet, despite the increased attention to STEM in policy and funding arenas, STEM education in some states is still lacking and requires a special attention.

Enquiry-based learning and deeper understanding has gained significant attention lately $[1,2]$. Due to its importance, lots of efforts focused recently on the K-12 STEM education. Recently many reforms have appeared to address the scientific reasoning, critical thinking, and problem solving approaches. One of the ways to address the enquiry-based learning is through regular structured and well-designed STEM activities [3-7]. In the last few years, STEM related activities have spread widely. STEM clubs, makers clubs, makers workshops, science show cases, and robotics competitions have been expanded across all the states. The host of these clubs/activities is normally school and public libraries, classrooms, and STEM related departments at university facilities. Almost all these activities target the K12 educators. Students involved in these makers or STEM activities are normally engaged in projects which progress in complexity and students are trained to be independent. Many universities have been involved in this movement in the last decade. Research universities have the infrastructure and the expertise to be a part of these STEM activities 
due to their readiness. Graduate and undergraduate students are normally the workhorse and play a significant rule in many activities. Although many of the STEM activities are conducted in-house, in many schools like New York University for example, graduate students have weekly-scheduled visits to nearby schools to educate K-12 about STEM related activities and nanotechnology. In August 2016 the NSU-LSMSA Makers Club was founded. The Club combines the Department of Engineering Technology (ET) at NSU and the LSMSA. The ET Department at NSU primarily offers two programs, B.S. in Industrial Engineering Technology (IET) and B.S. in Electronics Engineering Technology (EET). Both of these programs are accredited by the Accreditation Board for Engineering and Technology (ABET). It is worth mentioning that the IET program at NSU is the first and the only program in State of Louisiana. The ET program is technology-oriented, with a focus on a combination of basic theory, in-house practice, and projects, and hence it was selected as the host for this STEM activity. All practices were designed to enable students to gain the knowledge and hands-on experiences needed to further their professional and academic growth so that they can develop skills that will allow them to contribute meaningfully as engineering technology professionals.

The LSMSA is ranked by The Washington Post as one of the top public elite high schools in the nation. The LSMSA located in Natchitoches and resides on NSU campus. The school was conceived to offer a unique experience to the state's brightest students while supplying Natchitoches with an influx of commerce and attention. The School has strict admission criterion evaluated based on SAT/ACT results and recommendation. Hence, only top students make it to the school. Unlike other magnet schools, many of the instructors at the SLMSA are Ph.D. holders in their field of expertise. In addition, collegelevel classes are normally taught at LSMSA.

Due to close proximity between the Engineering Technology Department and LSMSA, collaboration has been established. STEM activities between LSMSA and NSU faculty began as independent studies where ET faculty mentor LSMSA students. In addition, the ET Faculty were also invited to present and discuss their research with the LSMSA students. This lead to a strengthening relationship between the two institutions, establishing the basis of the current collaboration. All students who conducted research at NSU pursed their degree in STEM related field. When the number of interested students in such projects increased, we decided to conduct this as a structured course/club. In August 2016 the NSULSMSA Makers Club was formed and established. The current enrollment of the club is 20 students. Participating students are taught theory and gain research and hands-on experiences at NSU laboratories and workshops. Great ideas from participating students related to energy and defense for example have been generated and proposed. Students currently are working on the design and implementation of their projects. The NSU-LSMSA Makers Club members meet three hours every week to interact, learn, and report progress.

The sections below, describe modules taught at the NSU-LSMSA Makers club in addition to other managerial and assessment aspects of this STEM related activities. Just to emphasize that the main objective of this Makers Club is to make students excited about STEM and to increase the number of students who are interested in STEM related careers. 


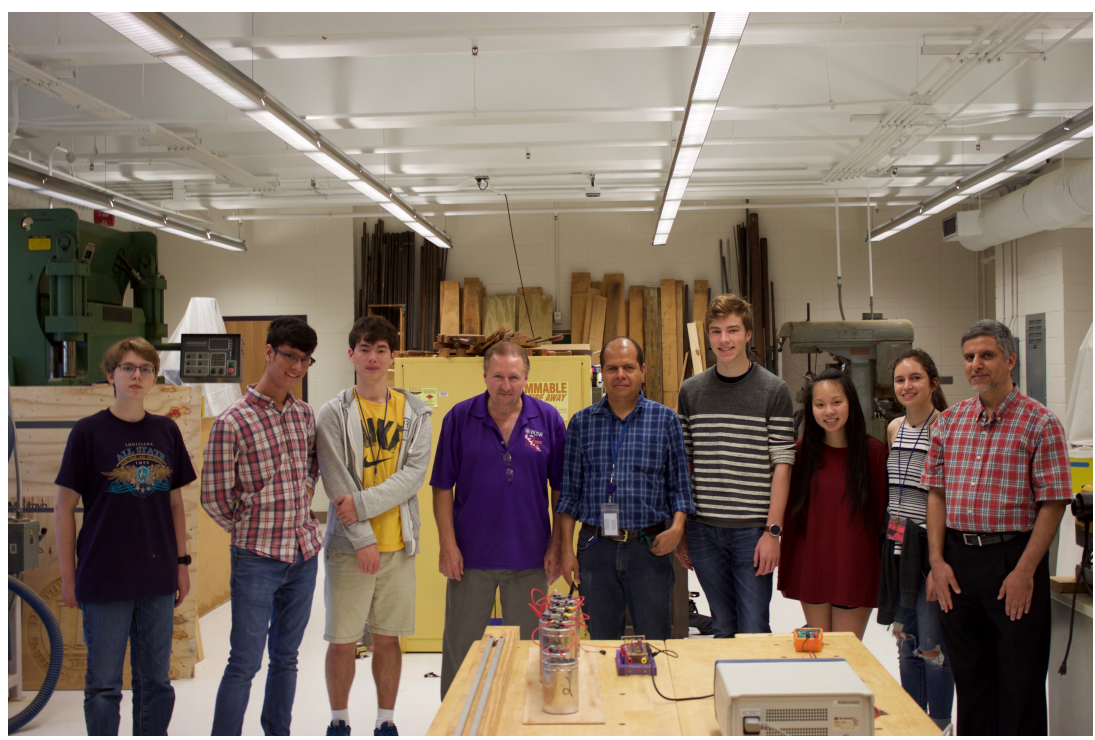

Figure 1. Representative members of the NSU-LSMSA Makers Club with their mentors and instructors. From Left to right, Dr. Jafar F. Al-Sharab, the founder and the director of the club, Cutrer McKenzie (student), Ngyen Hoa (student), Will Heitman (student), Dr. Mauricio Escobar (LSMA Instructor), Mr. Curtis Desselles (NSU lab. Manager), Alastair Dunn (student), Mathew Weick (student), and Mary Pace (student). Components on the table include aluminum rails, capacitors, and Cockcroft-Walton (CW) generator, or multiplier are the major components related to the electromagnetic launcher project.

\section{Materials taught at the NSU-LSMSA makers club:}

The NSU-LSMSA Makers Club meets twice a week for three hours. This is equivalent to 3credit hour course at the college level. The class is structured to deliver theory and basic science in addition to hands-on experience. The majority of students have a strong grasp of the basic scientific concepts and hence theoretical part was introduced as a refresher for one hour weekly. Theoretical subjects taught or reviewed to the participants in the NSULSMSA Makers Club include the fowling topics/modules:

- Basics of engineering design

- Alternating current principals and magnetism

- Applied digital electronics

- Introduction to Arduino and Raspberry Pi Microcontrollers

- Basics of soldering

- $\quad$ Circuit Design using Fritzing and Multisim simulations

Students at the makers club were exposed to and trained on many hands-on skills. The club has provided students with broad experience in metalworking through the use of tools, machines, and materials that are basic to complete their projects. Also, students 
were mentored and trained on both hand and machine-tools operations, and supplies. Hands-on experience and laboratory work include:

- Design using 123 Design and inventor

- 3D printing

- Noise maker soldering kit

- PCB board etching

- Circuit design, modeling, and simulation using Fritzing and Multisim

- Hand- and machine-tools

\section{Projects and ideas generated by participants:}

The NSU-LSMSA Makers Club boasted a significant number of students actively involved in researching their designed projects. The course is designed to have students propose a project or an experimental design within the first three weeks of classes, begin work on gathering data through the first part of the fall or spring semester, and compose the results in a comprehensive lab report. Each student presents his/her findings at the NSU annual research day held in late April [8]. The Engineering and Science faculty of both NSU and LSMSA attend the activity and serve as judges to this event as needed. Examples of projects designed and currently implemented by students include:

- Humanoid Robot: as a platform for machine learning, artificial intelligence, and computer vision research. This robot utilizes an advanced chip, Nvidia Jetson TX2 System, and will act as a platform for development in specific fields.

- Energy harvesting through a trampoline. In this project, students proposed design a sports machine where they can exercise and harvest energy simultaneously. The objective of this project is to create something fun and beneficial to the society. The students wants in extended the concept of energy harvesting to large stadiums.

- T-Shirt gun: The NSU university needed a T-Shirt gun to be used during the sports activities. The students responded to this call and they completed their initial design. Currently it is the stage of fabrication.

- Electromagnetic Launcher: Improved design and physics. A group of students were amazed by the concept and physics of electromagnetic launcher. Hence, they decided to prove the concept in the laboratory environment. Due to its extraordinary power, their idea is to use such a concept to send missions to explore other planets. Students wish to communicate with funding agencies such as NASA to support this project.

- Smart Controller: In this design, students noticed a waste of energy in their dormitory and they decided to design a smart controller, which can be modified and programmed via portable device such as cell phone and tablet. The concern of students is to save energy and to support our Green Campus Initiative.

- Solar Tracker: In this project, the students design, fabricate and program a solar tracker. A prototype is already fabricated. This project involved 3D printing, light sensors, and Arduino programming. 


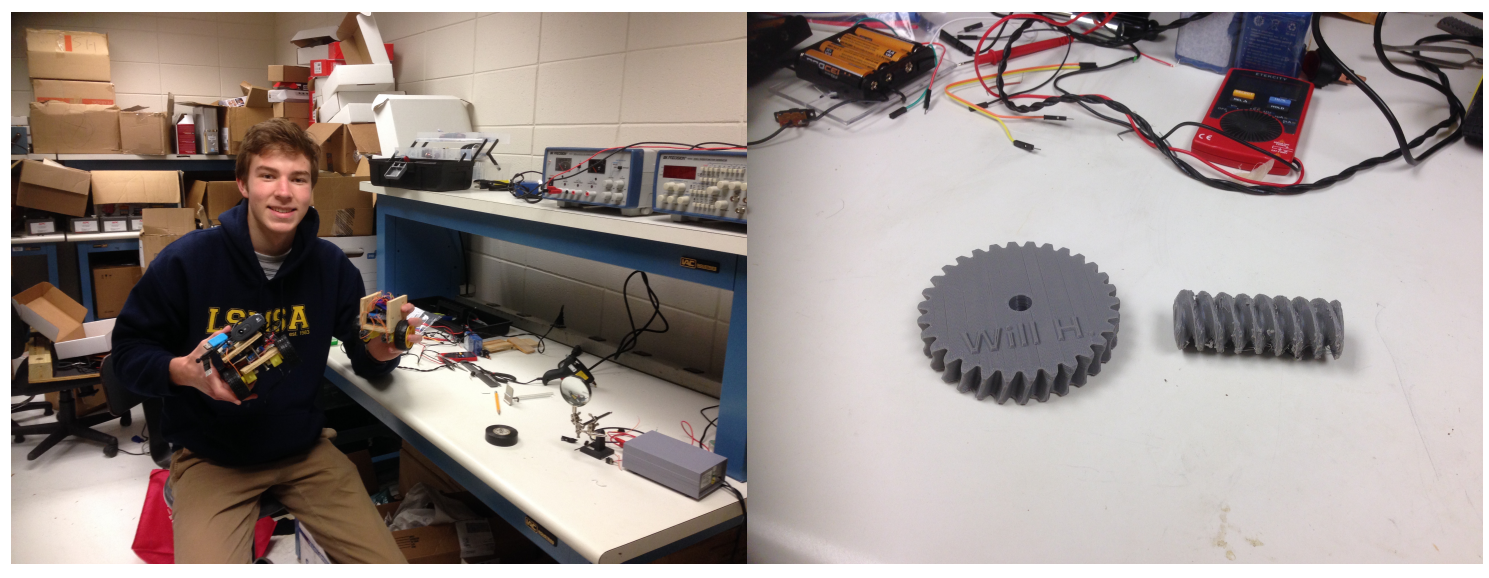

Figure 2. Will Heitman with his first Humanoid robot prototype. Picture on the right is a 3D printed worm wheel and driving gear to be used to control the expansion of the humanoid robot. Will describes his project briefly as follows: "My project focuses on social dynamics in robotics. This means producing a humanoid robot that can interact with humans without barriers or confusion. Currently, the project is in its third prototype, and is capable of detecting faces, balancing on two wheels, and performing basic tasks like connecting to a smartphone and managing power consumption. I'm currently working on building a strong, versatile architecture to build advanced behaviors with. Far later, I hope to connect the robot's behavior to a neural net, so that it can adapt and learn on the fly."

\section{Quality Assurance as a STEM module:}

The NSU-LSMSA Makers Club helps students to evolve as critical thinkers and sharpen their problem solving skills. Aerospace quality is one of the best and well-established practices, which emphasizes on the quality and failure prevention. With the aerospace quality education, students are now aware to change their project pattern from fix-fly-fail-fix-fly, to fix-fly, based on quality assurance. The participants on the NSU-LSMSA makers club were educated about quality through AAQ (Academy of Aerospace Quality) [9], a well established internet based forum for providing quality assurance training to academic institutions, commercial space service providers, technology development and other sectors.

The NSU-LSMSA Club director has participated in the annual AAQ workshop in August 2016 and, hence, he was invited to utilize the AAQ curriculum. The AAQ curriculum includes modules for all aspects of quality assurance necessary to ensure project success and provides a virtual community for networking and sharing of lessons-learned among like-minded scholars. For each topic, there is a training module, quizzes and multimedia materials. Modules which are related to current projects such as soldering, mechanical joining assembly, mechanical parts, problem solving, and robust design were discussed. 
The incorporation of quality assurance STEM activity for K-12 education system is probably one of the features, which distinguishes the NSU-LSMSA Makers Club from others.
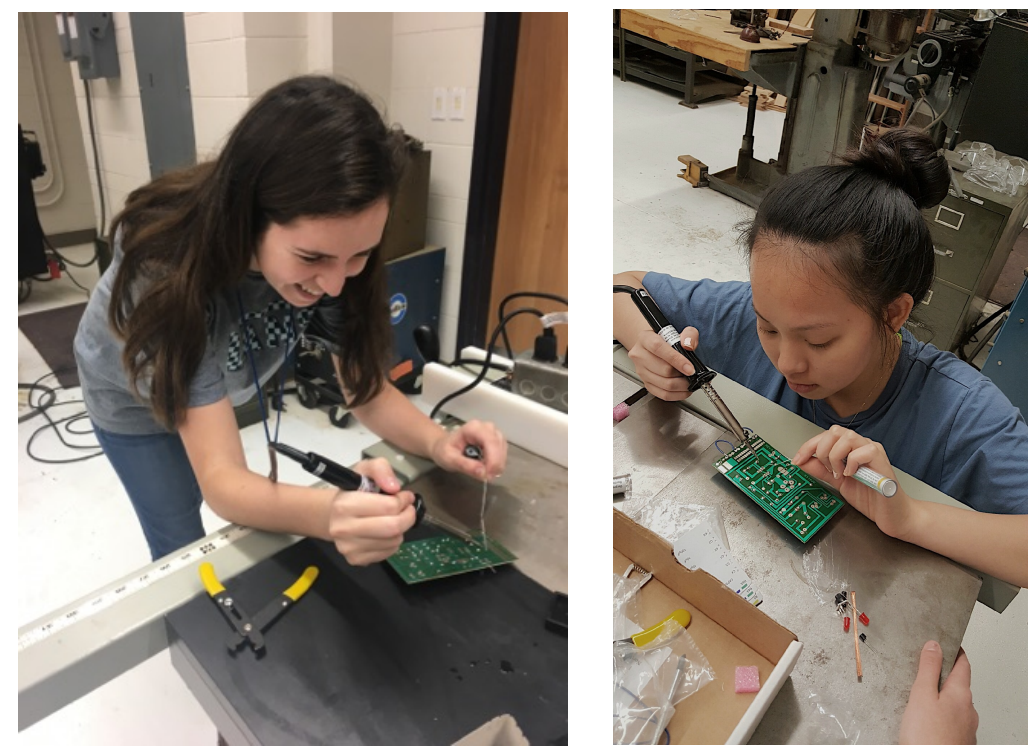

Figure 3. Cutrer McKenzie (left) and Ngyen Hoa (right) practicing soldering after completing the AAQ online soldering module.

\section{Dissemination of research results and findings:}

We always emphasize to our students that gaining research experience at the high school can improve their chances of getting into a top College/University. Many of our previous students who were serious and made good progress in their research were successful to secure full scholarship at high rank universities.

Participants in the NSU-LSMSA Makers Club generated great ideas, which are related energy harvesting, robotics, and launching devices. All these projects and ideas are very appealing and, more importantly apply basic science. Students were taught basic research procedure and they were encouraged to get credit by publishing their work in journals, conferences, and professional meetings. The Makers Club is designed to provide students not only with knowledge but also equip them with the essential skills in writing for publication such as how to write abstracts, papers, do oral presentations, and prepare posters. Publications of these projects include:

1. "NSU-LMSA makers club innovations", Benjamin Walker et. al. Accepted abstract for poster Presentation at the 2016 Defense Innovation Technology Summit. November 29-December 1, 201, at the JW Marriott, Austin, Texas.

2. Maximizing the solar energy harvesting through solar tracker, North Western State University Research Day, April 21, 2016. 
3. Humanoid Robot: Design and Fabrication, Hietman et. al., presented at the Northwestern State University Research Day, April 20, 2017.

4. Energy harvesting through a trampoline, Neupane et. al., presented at the Northwestern State University Research Day, April 20, 2017.

5. The design and fabrication of simple T-Shirt gun: Hoa et. al., presented at the Northwestern State University Research Day, April 20, 2017.

6. Smart controller design and fabrication. Benjamin Walker et al. The Smart Cities Connect Conference and Exhibition to be held in June at Austin Texas (to be presented).

\section{Mentorship and organization:}

One of the objectives of the NSU-LSMS Makers Clubs is to provide participants with mentors who can guide and motivate them to take an interest in STEM related field.

There are four faculty who are involved in organizing, and mentoring all various activities of the NSU-LSMSA makers club. Fifty percent (50\%) of mentors are from minority groups, Latino and Middle Eastern. Dr. Jafar F. Al-Sharab, Ph.D., from NSU is the establisher of the NSU-LSMSA Makers Club as well as other STEM related activities such as Robotics competition and Smart Structures Show (RC\&S3). He currently serves as the director and coordinator of the NSU-LSMSA Makers Club. In addition, he is involved in teaching electrical principals, digital electronics, and simulations skills. Dr. Robert Dalling, Ph.D. and Dr. Mauricio Escobar are the mentoring faculty from the LSMSA high school. Both, Dr. Dalling and Dr. Escobar are physics teachers. Mr. Curtis Desselles is a laboratory technician at NSU with extensive hands-on experience. He is in charged in teaching hand-on-skills to students. Mr. Desselles is a Ph.D. candidate and soon he will earn his doctorate degree.

\section{Rubrics-based assessment and evaluation of program modules:}

In order to check the performance and progress of students, the organizers decided to use rubrics based evaluation for the digital electronics course. The rubric was design to assess an ABET outcome: "An appropriate mastery of the knowledge, techniques, skills and modern tools of their disciplines, specifically the application of circuit analysis and design, computer programming, associated software, analog and digital electronics, and microcomputers to the building, testing, operation, and maintenance of electronic systems." The data will be collected by the end of the semester around May and will be analyzed according to the rubrics in Table I. Due to its importance and relative complexity, only digital concepts will be evaluated. In the future, the evaluation matrix will be broader. 
Table I. Analytic rubric for the digital electronics assessment

\begin{tabular}{|c|c|c|c|c|}
\hline Dimension & Unsatisfactory & Developing & satisfactory & Exemplary \\
\hline $\begin{array}{l}\text { Explain, analyze, } \\
\text { and define } \\
\text { introductory digital } \\
\text { concepts, basic } \\
\text { logic operations, } \\
\text { and basic logic } \\
\text { functions }\end{array}$ & $\begin{array}{l}\text { Does not show } \\
\text { any } \\
\text { understanding of } \\
\text { basic digital } \\
\text { concepts }\end{array}$ & $\begin{array}{l}\text { Understands some of the digital } \\
\text { concepts }\end{array}$ & $\begin{array}{l}\text { Understand the basic } \\
\text { introductory concepts }\end{array}$ & $\begin{array}{l}\text { Fully understand the } \\
\text { introductory digital } \\
\text { concepts }\end{array}$ \\
\hline $\begin{array}{l}\text { Explain, analyze, } \\
\text { and define number } \\
\text { systems, } \\
\text { operations, and } \\
\text { codes }\end{array}$ & $\begin{array}{l}\text { Does not } \\
\text { understand } \\
\text { Decimal, binary, } \\
\text { octal, and } \\
\text { hexadecimal }\end{array}$ & $\begin{array}{l}\text { Define Decimal, binary, octal, and } \\
\text { hexadecimal. }\end{array}$ & $\begin{array}{l}\text { Convert between decimal, } \\
\text { binary, octal, and } \\
\text { hexadecimal. }\end{array}$ & $\begin{array}{l}\text { Perform addition, } \\
\text { subtraction, } \\
\text { multiplications and } \\
\text { conversion without } \\
\text { mistakes. }\end{array}$ \\
\hline $\begin{array}{l}\text { Design, analyze, } \\
\text { build and test } \\
\text { combinational logic } \\
\text { circuits }\end{array}$ & $\begin{array}{l}\text { Unable to } \\
\text { identify various } \\
\text { logic gates in } \\
\text { combinational } \\
\text { circuit }\end{array}$ & $\begin{array}{l}\text { Able to identify various logic gates } \\
\text { in combinational circuit }\end{array}$ & $\begin{array}{l}\text { Produce a Truth Table } \\
\text { from combinational circuit }\end{array}$ & $\begin{array}{l}\text { Derive a logic circuit } \\
\text { from a given truth } \\
\text { table or a Karnaugh } \\
\text { map. }\end{array}$ \\
\hline
\end{tabular}




\section{Initial feedback from students:}

Students are successfully progressing in their projects. They enjoy the projects and it is fun for them. Feedback about the Makers Club is positive and encouraging. Due to time and space limitations we present comments from two students, namely Cutrer McKenzie and Ngyen Hoa:

\section{Cutrer McKenzie}

Although I have not been in it long, my experience in the Makers club has been great so far. It is full of opportunities that other classes do not offer. It really helps to prepare someone for engineering in college if that is what they want to do. My partner and I are currently building a T-shirt cannon that will reach about 300 feet. The soldering model we did taught the soldering terms, safety concerns, and how to handle it, which helped me perfect soldering for the first time on my Pc board.

\section{Ngyen Hoa}

The Maker's Club has been a pleasant experience for me so far. I join this class originally as I have a great interest in the engineering field and this could would give me a first-hand impression. I like how I am able to start and create any project I can think of as the materials and guidance will be here to assist me. My partner and I just started creating e a t-shirt cannon project to be used in NSU's events. The project will be able to shoot very far and it excites me thinking about the finished product.

My experience with the soldering module helped me understand more about soldering and the physics behind it. I have perfected my soldering technique after completing the AAQ soldering module. Since I have only recently learned how to solder, this module taught me how to perform it properly while learning the safety cautions and the technical terms.

\section{Future Plans for the NSU-LSMSA Makers Club:}

The NSU-LSMSA Makers Club will reach out to community for educational purposes. In the future, the Makers Club students will make demonstrations and will be engaged to inspire underprivileged students. This can be conducted by either inviting student to NSU-LSMSA facility or our Makers Club participants will make visits to the schools in the underprivileged areas.

One of the future plans of the NSU-LSMSA Makers Club is to develop a website for the club and incorporate online modules where students can review materials on their own and come prepared. In addition, the website will demonstrate the achievements of the club and post useful information to the community and other interested groups.

On the financial side, the future plan for the NSU-LSMSA Makers Club to target STEM related grants from the National Science Foundation (NSF) and other organizations to purchase scientific equipment to support research and learning activities for the Makers 
club. The Club is lacking some equipment such as microscopes, supplies, measuring tools, and digital components. In addition, students are very enthusiastic to travel to scientific conferences and, hence, the club will be seeking travel funds to cover theses activities.

\section{Conclusions:}

The main objective of the NSU-LSMSA Makers Club is increase the number of students who are interested in STEM related careers. We are very exited about the establishment of the NSU-LSMSA Makers Club. The results and achievements of the club are very promising and we are encouraged by these results. Participants were taught the engineering in a fun way. For the first time quality assurance was incorporated as STEM activity. Evaluation assessment using rubric will be used. Students were taught basics of research and how to develop into and independent thinkers and researchers. Participants were successful in presenting their work at professional meetings. The Makers Club is also to inform students about educational opportunities at host university, NSU. Although the club still in the inaugural year, the initial feedback from students about the NSU-LSMSA Makers Club is that they are very pleased with its activities and they would recommend it to their colleagues. Partnership between NSU and LSMSA will persist into the future and will work diligently to develop the future scientists and engineers.

\section{Acknowledgments:}

Support from the Department of Engineering Technology at Northwestern State University and the LSMSA foundation is highly appreciated. Thanks to Dr. Rondo Keele from Scholars College at Northwestern State University who proofread this manuscript.

\section{References:}

1. Bell, Randy L., Blair, Lesley M., Crawford, Barbara A., and Lederman, Norman G., “Just Do It? Impact of a Science Apprenticeship Program on High School Students' Understanding of the Nature of Science and Scientific Inquiry," Journal of Research in Science Teaching, Wiley Periodicals, Inc., 2003, 40(5), 487-509.

2. Anthony Badrige, Ashley Nutt, Mary Vaughn, Celis Hartley-Lewis, Amanda Amos, " The STEM Club at Marietta High School", ASEE Southeast Section Conference, 2009

3. O'Neill, D. Kevin, Plman, Joseph, L., 'Why Educate 'Little Scientists?' Examining the Potential of Practice-Based Scientific Literacy," Journal of Research in Science Teaching, Wiley Periodicals, Inc., 2004, 41(3), 234-266.

4. Iva Bojic, Juan F. Arratia, Vedran Podobnik, Mislav Grgic, "Supporting economically disadvantaged students from Nicaragua in STEM-C fields", Frontiers in Education Conference (FIE), IEEE publications, (2016), DOI: 10.1109/FIE.2016.77577526

5. I. Bojic , T. Jagust, and A. Sovic, "Selected examples of cooperation between universities and schools in STEM education ," in Proceedings of 5th IEEE Integrated STEM Education Conference, 2015 , pp. 189 - 194. 
6. I. Bojic and J. F. Arratia , "Teaching K-12 students STEM-C related topics through playing and conducting research " in Proceedings of 45th IEEE Frontiers in Education Conference, 2015 , pp. 1 - 8 .

7. A. Sovic , T. Jagust, and D. Sersic, "How to teach basic university-level programming concepts to first graders? " in Proceedings of 4th IEEE Integrated STEM Education Conference , 2014 , pp. $1-6$.

8. The AAQ (Academy of Aerospace Quality) is an online platform for quality assurance training. Modules and other related information can be accessed at http://aaq.auburn.edu/about

9. Northwestern State University (NSU) Research Day is an annual event where undergraduate and graduate students as well as faculty and staff can present their scholarly research and creative works in one of three formats. All NSU Research Day are normally posted at https://researchday.nsul 
